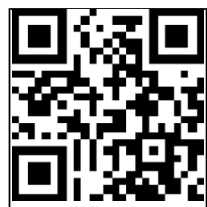

Editor's choice can to access mo free content

${ }^{1}$ AFIPE Research Group, Faculty of Physical Activity and Sports Sciences-INEF, Technical University of Madrid, Madrid, Spain

${ }^{2}$ Research Institute of the Hospital 12 de Octubre $(" i+12 ")$, Madrid, Spain ${ }^{3}$ Faculty of Health and Sport Science, University of Zaragoza, Huesca, Spain

${ }^{4}$ PROFITH "PROmoting FITness and Health through physical activity" research group, Faculty of Sport Sciences, Department of Physical Education and Sports, University of Granada, Granada, Spain

${ }^{5}$ European University, Madrid, Spain

Correspondence to Dr Ruben Barakat, AFIPE Research Group, Faculty of Physical Activity and Sports Sciences-INEF, Technical University of Madrid c/Martin Fierro 7, Madrid 28040, Spain barakatruben@gmail.com

Accepted 4 June 2015 Published Online First 1 July 2015

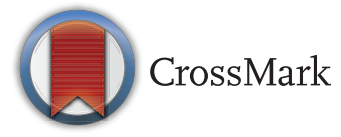

To cite: Barakat $R$, Perales M, Garatachea N, et al. Br I Sports Med 2015:49:1377-1381.

\title{
Exercise during pregnancy. A narrative review asking: what do we know?
}

Ruben Barakat, ${ }^{1}$ María Perales, ${ }^{1}$ Nuria Garatachea ${ }_{1}^{2,3}$ Jonatan R Ruiz, ${ }^{4}$ Alejandro Lucia ${ }^{2,5}$

\section{ABSTRACT}

Although there is no consensus as to whether exercise is beneficial during pregnancy, most studies report it poses no risk to either the mother or the fetus, and many suggest it to be beneficial to both. This review, which examines the evidence available, also reveals the many differences in study design followed, the type of exercise undertaken and the variables measured, which make it difficult to compare results. Advances in our understanding of the effects of exercise during pregnancy might best be made by undertaking randomised clinical trials with standardised protocols. However, most of the studies examining the relationship between exercise and pregnancy report no complications on maternal or fetal well-being. This is also in line with recent review studies advising that the pregnant population without obstetric contraindications should be encouraged to exercise during pregnancy. Therefore, the results of the present review stimulate those responsible for the healthcare of the pregnant woman to recommend moderate exercise throughout pregnancy without risk to maternal and fetal health.

\section{PARTICULARITIES OF PREGNANCY AND CHILDBIRTH}

The prenatal period is a unique physiological window during which many adaptations of the mother's body are required to secure the well-being of the fetus (figure 1 for a summary). ${ }^{1}{ }^{2}$ The success with which these are made can have major consequences for the long-term health of the child. $^{3}$

Cardiovascular changes begin during the fifth week of gestation and last until about a year after delivery. ${ }^{4-6}$ Cardiac output increases by about $40 \%$ (partly due to an increased stroke volume and partly to an increased heart rate) when there is only a $13 \%$ increase in the body mass to be supplied by the maternal blood. ${ }^{7}$ The blood volume also increases during pregnancy by some $40-50 \%,{ }^{8}$ while the systemic vascular resistance is markedly reduced, the vascular tone falling due to highplasma progesterone concentrations. ${ }^{9-11}$ The blood flow to the uterus is thus increased several fold.

During pregnancy, normal metabolic processes are altered to accommodate the needs of the developing fetus. ${ }^{2}$ The protein content of the maternal body tissues increases, and carbohydrates accumulate in the liver, muscles and placenta. In addition, fat deposits appear under the skin, especially around the breasts and buttocks, and elevated blood lipid and cholesterol levels are common. ${ }^{12}$ Salts of calcium, phosphorus and potassium, all essential for normal fetal development, also accumulate, and hormonal changes promote water retention. ${ }^{13}$ Maternal weight gain, normally some $10-13 \mathrm{~kg},{ }^{14}$ is one of the most obvious changes of pregnancy. The Institute of Medicine recommends weight gains for underweight, normal weight, overweight and obese women of 12.5-18, 11.5-16, 711.5 and $5-9 \mathrm{~kg}$, respectively. ${ }^{15-17}$

Extensive changes occur in the respiratory system during pregnancy, including anatomical and functional alterations; these occur early on under the influence of (mainly) progesterone, even before the growing uterus mechanically impairs ventilation. The diaphragm rises by about $4 \mathrm{~cm}$ due to a flaring of the lower ribs. ${ }^{12}$ This helps produce the slight increase in tidal volume and oxygen consumption $\left(\mathrm{VO}_{2}\right)$ noted in pregnant women, presumably to help supply the oxygen requirements of the fetus. ${ }^{18}$

The growing breast, uterus and fetus, along with increased lumbar lordosis, result in a shift in the mother's centre of gravity, which may cause balance problems. ${ }^{19}$ During pregnancy, hormonal changes are thought to induce a greater laxity of the joints, helping to soften the pubic symphysis and thus accommodate delivery. Increased joint laxity can, however, increase the risk of suffering strains or sprains. ${ }^{20}$

The hormonal changes that occur during pregnancy, modulated in part by the corpus luteum at the beginning of pregnancy, and later on by the fetoplacental unit and maternal endocrine glands, ${ }^{21}$ are responsible for many cardiovascular, respiratory and psychological changes. ${ }^{22}$ Increased levels of luteinising hormone, human growth hormone, human placental lactogen, oestrogen and progesterone are all seen during pregnancy. ${ }^{23}$

Pregnancy and childbirth have long been considered as risk factors in the genesis of pelvic floor dysfunction. ${ }^{24}{ }^{25}$ The intra-abdominal pressure generated by the growing uterus, as well as the mechanical strain imposed by the delivery process, may cause partial denervation of the pelvic floor and injury to the muscle and connective tissue. ${ }^{26} 27$ Several factors such as excessive maternal weight gain, fetal macrosomia, instrumental delivery or prolonged labour have traditionally been considered predisposing factors for pelvic floor injury, ${ }^{24} 28$ with the most common pelvis floor disorder being urinary incontinence. ${ }^{28}$

Pregnancy can also be a time of major emotional change. Many women suffer alterations in mood and even prenatal depression. ${ }^{29}$ According to the WHO (2002), 22\% of women of childbearing age have suffered depression at some point in their lives, with pregnancy making them more vulnerable 


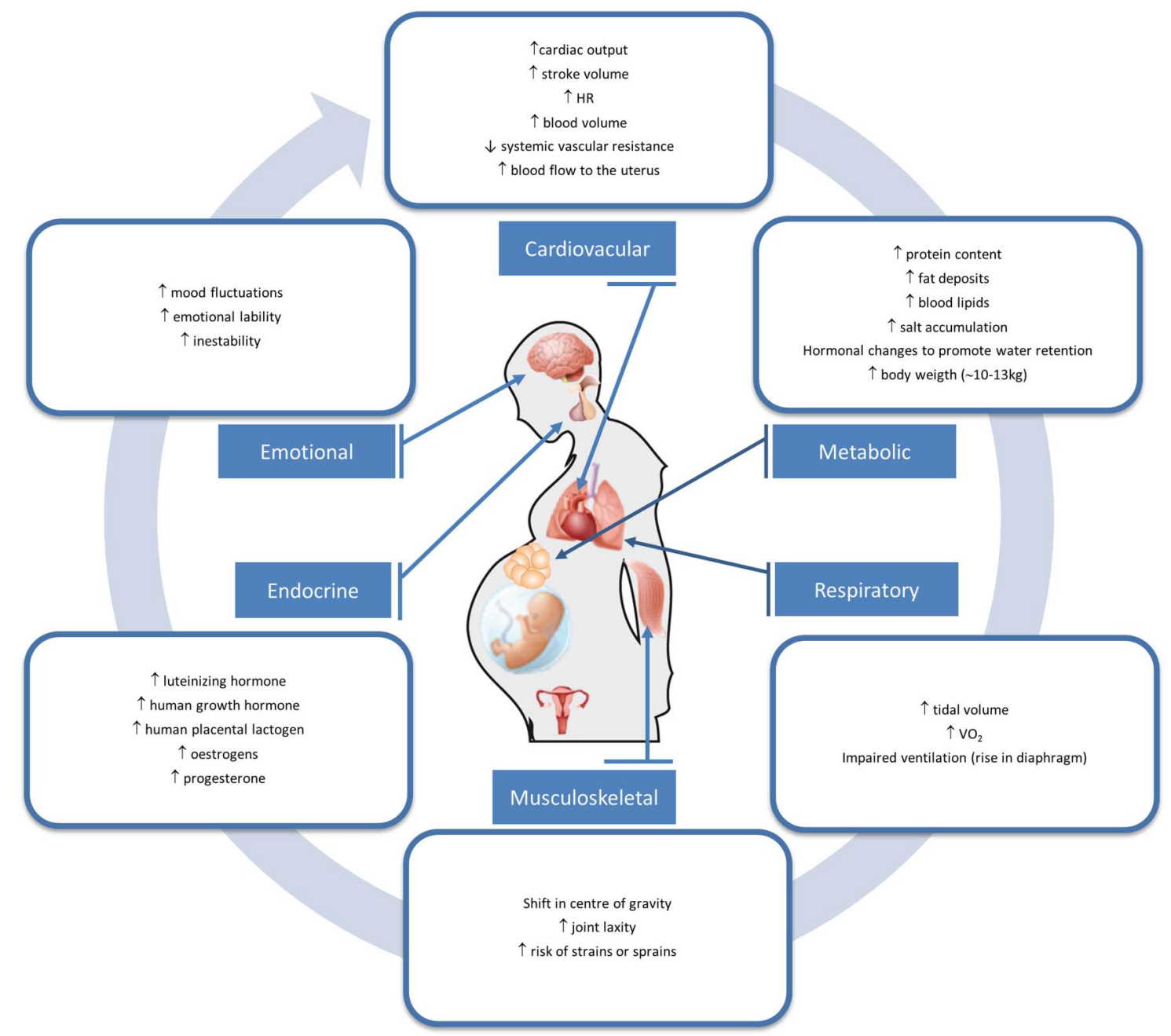

Figure 1 Main physiological adaptations of the mother's body during pregnancy ( $\mathrm{HR}$, heart rate; $\mathrm{VO}_{2}$, oxygen consumption).

compared with other times. ${ }^{30}$ In fact, recent studies have estimated the prevalence of depression during pregnancy to be between $10 \%$ and $30 \%,{ }^{31}$ higher than that recorded during the postpartum period. ${ }^{32}$

\section{EXERCISE AND PREGNANCY}

Physical exercise has become more popular among women of fertile age, and many now seek medical advice on whether they can continue exercising during pregnancy. ${ }^{33}$ The answer to their question demands that the influence of exercise on the mother and the fetus be properly understood. ${ }^{34}$ Recommendations regarding exercise during pregnancy have long been based more on social and cultural notions or 'common sense' than any hard scientific evidence. ${ }^{22}$ Indeed, the evidence on which they might be based is not particularly clear: studies on the effects of exercise on maternal and fetal health have been around for 30 years, yet controversy still surrounds how it affects many pregnancy outcomes, including gestational age at birth, the type of delivery, maternal weight gain or birth weight, among other outcomes. ${ }^{35}$ The reason for this lies partly in that observational studies have made much use of questionnaires-which are now known not to be very reliable in the assessment of physical activity-while experimental studies have involved such a range of type, duration and intensity of exercise that comparisons between them have been difficult. ${ }^{36}$

\section{Effects of exercise during pregnancy on maternal and fetal well-being \\ Hormonal and metabolic}

The growing fetus requires an adequate supply of nutrients, ${ }^{13}$ yet even the mildest form of acute exercise requires an increase in glucose uptake to the muscles. It is reported that acute exercise (as opposed to exercise training) in pregnant women is associated with increased sympathoadrenal and neurohumoral activity, resulting in reduced plasma insulin and increased norepinephrine, epinephrine, cortisol, glucagon and growth hormone concentrations. ${ }^{12} 37$ Soultanakis et al $^{38}$ compared the effect of $60 \mathrm{~min}$ of moderate-intensity exercise on glucose homeostasis in non-pregnant and pregnant women in their third trimester, measuring the rate at which, and the extent to which, blood glucose decreased, along with changes in lactate, $\beta$-hydroxybutyrate, free fatty acids (FFA) and insulin (all of which affect glucose homeostasis). Compared with the nonpregnant women, the blood glucose levels of the pregnant women were seen to decrease at a faster rate and to a significantly lower level post-exercise. Their insulin levels also decreased to a significantly lower level post-exercise, as did their lactate levels (but only for $15 \mathrm{~min}$ ). No difference was seen between the two groups in terms of their $\beta$-hydroxybutyrate levels. In a randomised clinical trial (RCT) involving 83 healthy pregnant women, Barakat et $a l^{39}$ examined the influence of a moderate-intensity exercise intervention over the entire 
pregnancy period on maternal glucose tolerance. The exercise group returned better maternal glucose screen results (103.8 $\pm 20.4 \mathrm{mg} / \mathrm{dL})$ than the control group $(126.9 \pm 29.5 \mathrm{mg} / \mathrm{dL})$. Bessinger et al ${ }^{40}$ examined substrate utilisation and hormonal responses to moderate-intensity exercise in a group of 12 women over gestation, measuring glucose, triglyceride, insulin, glucagon, cortisol, growth hormone and blood urea levels, as well as heart rate, $\mathrm{VO}_{2}$ and the respiratory exchange ratio at rest and after exercise. Urine urea, urine volume and creatinine levels were also measured $24 \mathrm{~h}$ before and after exercise. Pregnancy was associated with elevated resting triglyceride levels but a lower plasma glucose level. No significant differences were seen before and after exercise for most of the variables studied. It was concluded that substrate and hormonal responses to exercise are altered as pregnancy progresses, and that the reduced blood glucose level associated with exercise might be due more to impaired gluconeogenesis and glycogenolysis than any increase in glucose utilisation caused by exercise.

\section{Fetal growth and development}

Hopkins et $a l^{41}$ examined whether aerobic exercise training in the second half of pregnancy might be associated with reduced fetal size via changes in the maternal insulin-like growth factor (IGF) axis (which involves placental growth hormone), or via alterations in the plasma leptin or FFA concentrations. Training appeared to have no impact on the IGF axis, but the women in the exercise group experienced a $29 \%$ increase in plasma leptin concentration during late gestation and showed a trend towards lower FFA levels. The authors concluded that this increase in leptin might reflect subtle changes within the placenta in response to regular exercise, and that this might have contributed to the reduction seen in the size and birth weight of the children they bore.

Studies on the effect of physical exercise on fetal growth and development have reported varying results, perhaps again because of the variety of designs used and the different interventions followed (type, intensity, duration and frequency of maternal exercise). Some studies report poorer growth in infants of physically active mothers, ${ }^{42-45}$ while others report the opposite, ${ }^{46}$ and yet others report no difference at all. ${ }^{47}{ }^{48}$ In an RCT to determine the effects of aerobic exercise training during the second half of pregnancy on maternal insulin sensitivity and neonatal outcomes, Hopkins et $a l^{44}$ observed lower birth weights and body mass indices at birth for the offspring of mothers who exercised. Clapp et $a l^{49} 50$ reported a positive association between early and regular physical exercise during normal pregnancy and improved fetoplacental growth. Some authors suggest that maternal exercise during pregnancy has no adverse effects on infants during their first year of life, ${ }^{51}$ nor does it affect children's subcutaneous fat mass 5 years after delivery. ${ }^{52}$ In a cohort study with follow-up at 1 year, Edwards $^{43}$ found exercise during pregnancy to have no influence on morphometric variables or cognitive performance as measured with the Bayley mental scale.

\section{Respiratory}

The respiratory response to maternal exercise is particularly related to hormonal factors. In theory, changes in the endocrine system during pregnancy could lead to changes in breathing responses, perhaps even limiting exercise capacity. ${ }^{53}$ It has been suggested that hormonal changes and respiratory responses to exercise may also be partly responsible for pregnant women's perception of having to make an increased effort during exercise. ${ }^{54}$ However, Jensen et $a l^{53}$ report pregnancy and advancing gestation not to be associated with increased exertional respiratory discomfort, nor any reduction in aerobic work capacity, and indicate that mechanical adaptations during pregnancy help pregnant women achieve a peak oxygen consumption $\left(\mathrm{VO}_{2 \text { peak }}\right)$ similar to that of non-pregnant women. Jensen et l $^{55}$ also studied the physiological mechanisms of exertional breathlessness in responses to incremental cycle exercise in 15 young, healthy women 34-38 weeks into gestation, and again 45 months into the postpartum period. Pregnancy-induced increases in exertional breathlessness were found to reflect an increased ventilation and respiratory muscle effort, and dynamic mechanical ventilatory constraints contributed to respiratory discomfort near the limits of tolerance in late gestation. In an experimental study in 28 previously sedentary pregnant women, McAuley et $a l^{56}$ examined the effects of aerobic conditioning during the second and third trimesters on ventilatory responses. The results showed that regular maternal exercise had no significant effect on pregnancy-induced changes in ventilation or alveolar gas exchange at rest or during standard submaximal exercise. In the authors' opinion, prenatal fitness programmes improve the workload capacity, as shown by the improvement in ventilation and peak oxygen pulse values. Wolfe et al ${ }^{57}$ reported similar results. In a study designed to examine the size of the increased ventilatory response to exercise in pregnancy, Jensen $e t a l^{58}$ reported the variation in this variable, as well as the perceived breathlessness among healthy pregnant women, to be explained by interindividual variation in the ventilatory recruitment threshold for $\mathrm{CO}_{2}$.

\section{Cardiovascular}

Pivarnik et $a l^{59}$ found that the cardiorespiratory response to acute exercise in pregnant women who were physically active throughout pregnancy was better than in women who remained inactive during gestation. Veille et $a l^{60}$ studied left ventricular diastolic filling in response to exercise (stationary bicycle exercise) by transmitral pulsed Doppler echocardiography in 10 healthy pregnant women during each trimester of pregnancy, and again at 12 weeks after delivery. Measurements were made at rest and during exercise at each workload. Pregnancy increased the early and atrial peak flow velocities and reduced the P-R interval, the early deceleration time and the isovolumetric relaxation time. The authors concluded that the responders experienced an increase in left ventricular chamber stiffness during maximum intensity exercise. Morrow et $a l^{61}$ studied maternal heart rate and blood pressure (BP), and the uteroplacental/umbilical circulation (by Doppler ultrasound) in 15 healthy, pregnant women who undertook a $5 \mathrm{~min}$ exercise period in late pregnancy. Maternal heart rate and BP were increased by the exercise, as was the ratio of the systolic/diastolic velocity in the uterine artery. This suggests an increase in uteroplacental vascular resistance. The fetal heart rate was also increased by the exercise, but the systolic/diastolic velocity ratio in the umbilical artery remained unaltered. These authors concluded that exercise generates resistance to blood flow in the uterine circulation. In a recent longitudinal study involving 27 healthy, nulliparous, pregnant women, Ferreira et $a l^{62}$ examined whether maternal heart rate and BP changed in response to pelvic floor muscle training during pregnancy. Systolic and diastolic BP were measured before and after each training session and maternal heart rate was measured during each session. The intervention programme followed involved individual supervised pelvic floor muscle training between gestational weeks 20 36. The authors reported that this had no effect on BP but significantly increased the heart rate during the exercise session, 


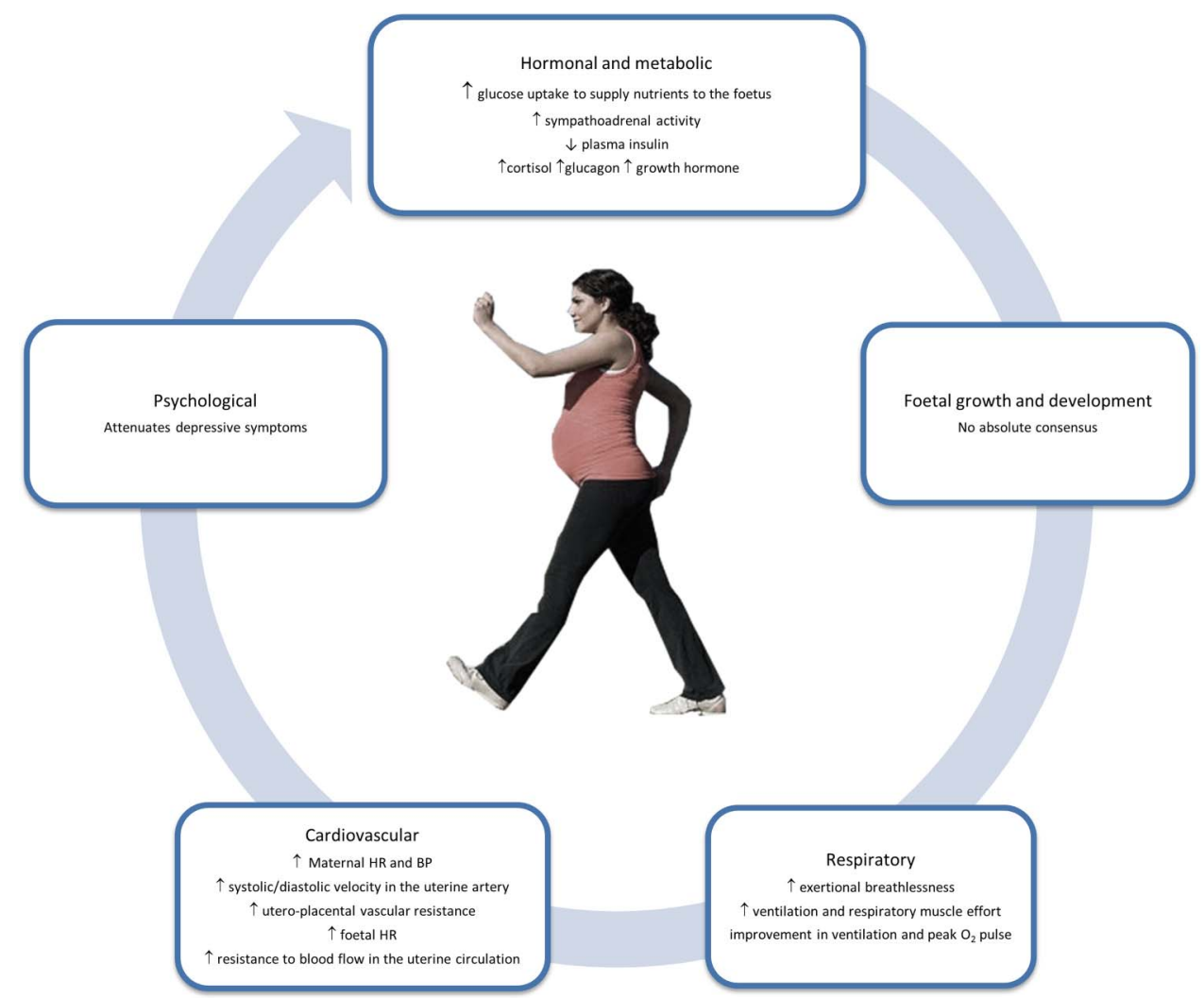

Figure 2 Main effects of exercise during pregnancy on maternal and fetal well-being (BP, blood pressure; HR, heart rate; $\mathrm{O}_{2}$, oxygen).

with no negative long-term effect on either of these variables. In a prospective study involving 22 sedentary normal weight, overweight and obese pregnant women, Stutzman et $a l^{63}$ investigated the effect of an exercise programme on BP and cardiac autonomic function as determined by heart rate variability (heart rate) and baroreflex sensitivity (BRS). The exercise programme consisted of walking (low-intensity exercise) for 16 weeks (from week 20 of pregnancy onwards). The BP, heart rate and BRS were measured at rest and at the beginning of exercise both at the beginning and end of the experimental period. Increases were seen in BP, heart rate and BRS, particularly in the overweight women. It was suggested that exercise training might attenuate the increase in $\mathrm{BP}$ and the loss of parasympathetic tone associated with pregnancy, especially in overweight women.

\section{Psychological}

Pregnancy is a time during which emotional balance and psychological stability can be at risk. Depression can be difficult to treat in pregnant women given the need to avoid possible adverse effects such as impaired fetal brain development, ${ }^{64-66}$ preterm delivery or intrauterine growth restriction, ${ }^{67-69}$ postpartum depression and its related complications, mother-infant bonding difficulties, ${ }^{70}$ infant feeding difficulties and childhood overweight problems, ${ }^{71}$ low birth weight or longer hospital stays. ${ }^{70}$ Theoretically, improvements in mood and self-esteem generated by exercise might mitigate this problem and improve body satisfaction. ${ }^{72}$ Certainly, this association has been shown in some studies. ${ }^{73}{ }^{74}$ Other studies have shown that exercise during pregnancy improves depression-related symptoms. ${ }^{75-77}$ In a recent RCT, Perales et $a l^{78}$ found that a programme of physical exercise throughout pregnancy attenuated such symptoms in otherwise healthy, pregnant women.
Pelvic Floor

Some studies have reported a beneficial effect of programmes aiming at strengthening the pelvic floor muscles during pregnancy in symptoms of urinary incontinence. ${ }^{79-83}$ Further, a systematic review by Mørkved and $\mathrm{B}^{84}$ showed a positive effect of specific pelvic floor muscle training during pregnancy in the prevention and treatment of urinary incontinence. Yet such types of training programmes would not be as effective if they are simply included within general fitness classes for pregnant women with no individual instructions and specifications regarding the correct contraction of pelvic floor muscles. ${ }^{85}$ In a recent study on complications to the opening of the pelvic floor during labour (levator hiatus muscle action), Bø et al ${ }^{86}$ reported no differences in women exercising regularly before or during pregnancy compared with their non-exercising referents.

Figure 2 shows a summary of the main effects of exercise during pregnancy on maternal and fetal well-being.

\section{Effects of exercise on maternal outcomes of pregnancy}

Examining pregnancy outcomes is the most reliable way of determining whether pregnancy and childbirth have been successful. The most important maternal outcomes are discussed below.

\section{Maternal weight gain}

This varies widely among pregnant women, ${ }^{87}$ but a very highpercentage gain excessive weight. ${ }^{88}{ }^{89}$ Unfortunately, this is associated with hypertension, gestational diabetes and fetal macrosomia. ${ }^{88} 90-92$ Exercise may help in the control of maternal weight gain, ${ }^{93-95}$ and may help in its treatment in overweight and obese pregnant women. ${ }^{96}$

Gestational age at delivery

Sufficient time is required for the organs and systems of the fetus to reach maturity. ${ }^{97}$ It has traditionally been thought that 


\section{What are the new findings?}

- In the absence of obstetric complications, the healthy pregnant body is able to cope with the physiological demands imposed by moderate exercise.

- Moderate exercise is not a risk factor for fetal and maternal pregnancy outcomes.

- A supervised programme of moderate exercise throughout pregnancy may be recommended by health professionals to attenuate the risk of pregnancy alterations.

exercise, especially high-intensity exercise, might lead to earlier parturition, mainly due to hormonal factors. ${ }^{12} 98$ However, several recent studies suggest that moderate-intensity exercise does not lead to earlier births in healthy pregnant women. ${ }^{36}$ 99-101

\section{Type of delivery}

The mode of delivery can affect the well-being of the mother and the newborn. Instrumental delivery or Caesarean section can have many sequelae that condition postpartum recovery. While earlier studies found no influence of exercise on type of delivery, ${ }^{102}{ }^{103}$ more recent studies suggest that an association exists between exercise during pregnancy and a reduced need for Caesarean section. ${ }^{104} 105$

\section{Duration of labour}

The duration of childbirth can affect the well-being of both the mother and the newborn. ${ }^{106}$ Prolonged labour is associated with increased maternal and perinatal morbidity and mortality. ${ }^{107-109}$ Identified maternal morbidities include maternal exhaustion, electrolyte imbalance, hypoglycaemia, obstructed labour and its sequelae (such as uterine rupture, primary postpartum haemorrhage) and obstetric fistula. Prolonged labour can also cause fetal distress, perinatal asphyxia, the need for neonatal resuscitation and admission into a neonatal intensive care unit, hypoxic ischaemic encephalopathy and cerebral palsy. ${ }^{110}$ In theory, physical fitness could positively influence the course of labour by reducing excessive weight gain and inducing metabolic and hormonal changes that may impact uterine contractility and endurance. ${ }^{111}$ Ruiz et $a l^{95}$ found no effect of lightintensity to moderate-intensity aerobic and resistance exercise on duration of labour in 481 pregnant women who exercised from the ninth week of pregnancy compared with their counterparts $(n=481)$ who did not exercise.

\section{FUTURE PERSPECTIVES}

Much controversy remains regarding the effects of exercise during pregnancy. It is important that studies be performed using standardised protocols that would allow later comparisons of the results obtained by different authors. The undertaking of such studies, especially RCTs, might afford more reliable answers. Currently, it would appear that moderate exercise performed throughout pregnancy is beneficial to the mother while having no adverse effects on the growing fetus.

Funding This study was partially supported by the Spanish Ministry of Economy and Competitiveness (RYC-2010-05957) and Technical University of Madrid (AL15-PID-06). Research in the field of exercise and health by Alejandro Lucia is funded by the Fondo de Investigaciones Sanitarias (FIS, grant number PI12/00914) and fondos FEDER.

Competing interests None declared.

Provenance and peer review Not commissioned; externally peer reviewed.

\section{REFERENCES}

1 Wolfe LA, Brenner IK, Mottola MF. Maternal exercise, fetal well-being and pregnancy outcome. Exerc Sport Sci Rev 1994;22:145-94.

2 Wolfe LA, Ohtake PJ, Mottola MF, et al. Physiological interactions between pregnancy and aerobic exercise. Exerc Sport Sci Rev 1989;17:295-351.

3 Hopkins SA, Cutfield WS. Exercise in pregnancy: weighing up the long-term impact on the next generation. Exerc Sport Sci Rev 2011;39:120-7.

4 Clapp JF III, Capeless E. Cardiovascular function before, during, and after the first and subsequent pregnancies. Am J Cardiol 1997;80:1469-73.

5 Duvekot JJ, Cheriex EC, Pieters FA, et al. Early pregnancy changes in hemodynamics and volume homeostasis are consecutive adjustments triggered by a primary fall in systemic vascular tone. Am J Obstet Gynecol 1993;169:1382-92.

6 Robson SC, Hunter S, Boys RJ, et al. Serial study of factors influencing changes in cardiac output during human pregnancy. Am J Physiol 1989;256(4 Pt 2): H1060-5.

7 Geva T, Mauer MB, Striker L, et al. Effects of physiologic load of pregnancy on left ventricular contractility and remodeling. Am Heart J 1997;133:53-9.

8 Gilson GJ, Samaan S, Crawford MH, et al. Changes in hemodynamics, ventricular remodeling, and ventricular contractility during normal pregnancy: a longitudinal study. Obstet Gynecol 1997:89:957-62.

9 Bamfo JE, Kametas NA, Nicolaides KH, et al. Maternal left ventricular diastolic and systolic long-axis function during normal pregnancy. Eur J Echocardiogr 2007;8:360-8.

10 Carbillon L, Uzan M, Uzan S. Pregnancy, vascular tone, and maternal hemodynamics: a crucial adaptation. Obstet Gynecol Surv 2000;55:574-81.

11 Zentner $D$, Wheeler $M$, Grigg L. Does pregnancy contribute to systemic right ventricular dysfunction in adults with an atrial switch operation? Heart Lung Circ 2012;21:433-8.

12 Artal R, Wiswell R, Drinkwater B. Exercise in pregnancy. Williams \& Willkins, 1991

13 Bonen A, Campagna PD, Gilchrist L, et al. Substrate and hormonal responses during exercise classes at selected stages of pregnancy. Can J Appl Physiol 1995:20:440-51.

14 Davenport MH, Ruchat SM, Giroux I, et al. Timing of excessive pregnancy-related weight gain and offspring adiposity at birth. Obstet Gynecol 2013;122(2 Pt 1):255-61.

15 Frederick IO, Williams MA, Sales AE, et al. Pre-pregnancy body mass index, gestational weight gain, and other maternal characteristics in relation to infant birth weight. Matern Child Health J 2008;12:557-67.

16 Medicine IO. Nutrition during pregnancy: part I weight gain and part II nutrient supplements. Washington DC: National Academies Press, 1990.

17 Zhou W, Olsen J. Gestational weight gain as a predictor of birth and placenta weight according to pre-pregnancy body mass index. Acta Obstet Gynecol Scand 1997:76:300-7.

18 Pivarnik JM, Stein AD, Rivera JM. Effect of pregnancy on heart rate/oxygen consumption calibration curves. Med Sci Sports Exerc 2002;34:750-5.

19 Wang TW, Apgar BS. Exercise during pregnancy. Am Fam Physician 1998;57:1846-52, 57.

20 Shephard RJ. Exercise and training in women, part I: influence of gender on exercise and training responses. Can J Appl Physiol 2000;25:19-34.

21 Wolfe LA, Mottola MF. Aerobic exercise in pregnancy: an update. Can J App/ Physiol 1993;18:119-47.

22 Sternfeld B. Physical activity and pregnancy outcome. Review and recommendations. Sports Med 1997;23:33-47.

23 Asher I, Kaplan B, Modai I, et al. Mood and hormonal changes during late pregnancy and puerperium. Clin Exp Obstet Gynecol 1995;22:321-5.

24 Chitra TV, Panicker S. Child birth, pregnancy and pelvic floor dysfunction. J Obstet Gynaecol India 2011;61:635-7.

25 van Veelen GA, Schweitzer KJ, van der Vaart $\mathrm{CH}$. Ultrasound imaging of the pelvic floor: changes in anatomy during and after first pregnancy. Ultrasound Obstet Gynecol 2014;44:476-80

26 MacLennan AH, Taylor AW, Wilson DH, et al. The prevalence of pelvic floor disorders and their relationship to gender, age, parity and mode of delivery. BJOG 2000;107:1460-70.

27 Zhu L, Li L, Lang JH, et al. Prevalence and risk factors for peri- and postpartum urinary incontinence in primiparous women in China: a prospective longitudinal study. Int Urogynecol J 2012;23:563-72.

28 Solans-Domenech M, Sanchez E, Espuna-Pons M, Pelvic Floor Research G. Urinary and anal incontinence during pregnancy and postpartum: incidence, severity, and risk factors. Obstet Gynecol 2010;115:618-28.

29 Reading AE, Cox DN, Sledmere CM, et al. Psychological changes over the course of pregnancy: a study of attitudes toward the fetus/neonate. Health Psychol 1984:3:211-21

30 Campagne DM. The obstetrician and depression during pregnancy. Eur I Obstet Gynecol Reprod Biol 2004:116:125-30.

31 Teixeira C, Figueiredo B, Conde A, et al. Anxiety and depression during pregnancy in women and men. J Affect Disord 2009;119:142-8. 
32 Lee AM, Lam SK, Sze Mun Lau SM, et al. Prevalence, course, and risk factors for antenatal anxiety and depression. Obstet Gynecol 2007;110:1102-12.

33 Madsen $M$, Jorgensen $T$, Jensen $M L$, et al. Leisure time physical exercise during pregnancy and the risk of miscarriage: a study within the Danish National Birth Cohort. BJOG 2007;114:1419-26

34 Barakat R, Pelaez M, Montejo R, et al. Exercise during pregnancy improves maternal health perception: a randomized controlled trial. Am J Obstet Gynecol 2011;204:402.e1-7.

35 Downs DS, Chasan-Taber L, Evenson KR, et al. Physical activity and pregnancy: past and present evidence and future recommendations. Res $Q$ Exerc Sport 2012;83:485-502.

36 Barakat $R$, Pelaez $M$, Montejo $R$, et al. Exercise throughout pregnancy does not cause preterm delivery: a randomized, controlled trial. J Phys Act Health 2014;11:1012-17.

37 Bessinger RC, McMurray RG. Substrate utilization and hormonal responses to exercise in pregnancy. Clin Obstet Gynecol 2003;46:467-78.

38 Soultanakis HN, Artal R, Wiswell RA. Prolonged exercise in pregnancy: glucose homeostasis, ventilatory and cardiovascular responses. Semin Perinatol 1996;20:315-27

39 Barakat R, Cordero Y, Coteron J, et al. Exercise during pregnancy improves maternal glucose screen at 24-28 weeks: a randomised controlled trial. $\mathrm{Br} \mathrm{J}$ Sports Med 2012;46:656-61.

40 Bessinger RC, McMurray RG, Hackney AC. Substrate utilization and hormonal responses to moderate intensity exercise during pregnancy and after delivery. Am J Obstet Gynecol 2002;186:757-64.

41 Hopkins SA, Baldi JC, Cutfield WS, et al. Effects of exercise training on maternal hormonal changes in pregnancy. Clin Endocrinol 2011;74:495-500.

42 Clapp JF III, Capeless EL. Neonatal morphometrics after endurance exercise during pregnancy. Am J Obstet Gynecol 1990;163(6 Pt 1):1805-11.

43 Edwards $G$. Does regular exercise during pregnancy affect the physical growth or mental development of infants? West J Med 1999;170:264.

44 Hopkins SA, Baldi JC, Cutfield WS, et al. Exercise training in pregnancy reduces offspring size without changes in maternal insulin sensitivity. J Clin Endocrinol Metab 2010;95:2080-8.

45 Juhl M, Olsen J, Andersen PK, et al. Physical exercise during pregnancy and fetal growth measures: a study within the Danish National Birth Cohort. Am J Obstet Gynecol 2010;202:63.e1-8.

46 Hatch MC, Shu XO, McLean DE, et al. Maternal exercise during pregnancy, physical fitness, and fetal growth. Am J Epidemiol 1993;137:1105-14.

47 Kardel KR, Kase T. Training in pregnant women: effects on fetal development and birth. Am J Obstet Gynecol 1998;178:280-6.

48 Owe KM, Nystad W, Bo K. Association between regular exercise and excessive newborn birth weight. Obstet Gynecol 2009;114:770-6.

49 Clapp JF III, Kim H, Burciu B, et al. Beginning regular exercise in early pregnancy: effect on fetoplacental growth. Am J Obstet Gynecol 2000;183:1484-8.

50 Clapp JF III, Kim H, Burciu B, et al. Continuing regular exercise during pregnancy: effect of exercise volume on fetoplacental growth. Am J Obstet Gynecol 2002;186:142-7.

51 Clapp JF III, Simonian S, Lopez B, et al. The one-year morphometric and neurodevelopmental outcome of the offspring of women who continued to exercise regularly throughout pregnancy. Am J Obstet Gynecol 1998;178:594-9.

52 Clapp JF III. Morphometric and neurodevelopmental outcome at age five years of the offspring of women who continued to exercise regularly throughout pregnancy. J Pediatr 1996;129:856-63.

53 Jensen D, Webb KA, Wolfe LA, et al. Effects of human pregnancy and advancing gestation on respiratory discomfort during exercise. Respir Physiol Neurobiol 2007;156:85-93.

54 Milne JA, Howie AD, Pack Al. Dyspnoea during normal pregnancy. Br J Obstet Gynaecol 1978;85:260-3.

55 Jensen D, Webb KA, Davies GA, et al. Mechanical ventilatory constraints during incremental cycle exercise in human pregnancy: implications for respiratory sensation. J Physiol 2008;586(Pt 19):4735-50.

56 McAuley SE, Jensen D, McGrath MJ, et al. Effects of human pregnancy and aerobic conditioning on alveolar gas exchange during exercise. Can J Physiol Pharmacol 2005;83:625-33.

57 Wolfe LA, Walker RM, Bonen A, et al. Effects of pregnancy and chronic exercise on respiratory responses to graded exercise. J Appl Physiol 1994;76:1928-36.

58 Jensen $D$, Webb KA, O'Donnell DE. The increased ventilatory response to exercise in pregnancy reflects alterations in the respiratory control systems ventilatory recruitment threshold for CO2. Respir Physiol Neurobiol 2010;171:75-82.

59 Pivarnik JM, Ayres NA, Mauer MB, et al. Effects of maternal aerobic fitness on cardiorespiratory responses to exercise. Med Sci Sports Exerc 1993;25:993-8.

60 Veille JC, Kitzman DW, Millsaps PD, et al. Left ventricular diastolic filling response to stationary bicycle exercise during pregnancy and the postpartum period. Am J Obstet Gynecol 2001;185:822-7.

61 Morrow RJ, Ritchie JW, Bull SB. Fetal and maternal hemodynamic responses to exercise in pregnancy assessed by Doppler ultrasonography. Am J Obstet Gynecol 1989;160:138-40.
62 Ferreira $\mathrm{CH}$, Naldoni LM, Ribeiro Jdos $\mathrm{S}$, et al. Maternal blood pressure and heart rate response to pelvic floor muscle training during pregnancy. Acta Obstet Gynecol Scand 2014;93:678-83

63 Stutzman SS, Brown CA, Hains SM, et al. The effects of exercise conditioning in normal and overweight pregnant women on blood pressure and heart rate variability. Biol Res Nurs 2010;12:137-48.

64 Allister L, Lester BM, Carr S, et al. The effects of maternal depression on fetal heart rate response to vibroacoustic stimulation. Dev Neuropsychol 2001;20:639-51.

65 Diego MA, Field T, Hernandez-Reif M, et al. Prenatal depression restricts fetal growth. Early Hum Dev 2009;85:65-70.

66 O'Connor TG, Heron J, Golding J, et al. Maternal antenatal anxiety and children's behavioural/emotional problems at 4 years. Report from the Avon Longitudinal Study of Parents and Children. Br J Psychiatry 2002;180:502-8.

67 Field T. Prenatal depression effects on early development: a review. Infant Behav Dev 2011;34:1-14.

68 Field T, Diego M, Hernandez-Reif M. Prenatal depression effects on the fetus and newborn: a review. Infant Behav Dev 2006;29:445-55.

69 Li D, Liu L, Odouli R. Presence of depressive symptoms during early pregnancy and the risk of preterm delivery: a prospective cohort study. Hum Reprod 2009:24:146-53.

70 Wisner KL, Sit DK, Hanusa BH, et al. Major depression and antidepressant treatment: impact on pregnancy and neonatal outcomes. Am J Psychiatry 2009; 166:557-66

71 Ertel KA, Koenen KC, Rich-Edwards JW, et al. Antenatal and postpartum depressive symptoms are differentially associated with early childhood weight and adiposity. Paediatr Perinat Epidemiol 2010;24:179-89.

72 Boscaglia N, Skouteris $\mathrm{H}$, Wertheim $\mathrm{EH}$. Changes in body image satisfaction during pregnancy: a comparison of high exercising and low exercising women. Aust N Z J Obstet Gynaecol 2003;43:41-5.

73 Mehta UJ, Siega-Riz AM, Herring AH. Effect of body image on pregnancy weight gain. Matern Child Health J 2011;15:324-32.

74 Rauff EL, Downs DS. Mediating effects of body image satisfaction on exercise behavior, depressive symptoms, and gestational weight gain in pregnancy. Ann Behav Med 2011;42:381-90.

75 Craft LL, Freund KM, Culpepper L, et al. Intervention study of exercise for depressive symptoms in women. J Womens Health (Larchmt) 2007;16:1499-509.

76 Koniak-Griffin D. Aerobic exercise, psychological well-being, and physical discomforts during adolescent pregnancy. Res Nurs Health 1994;17:253-63.

77 Robledo-Colonia AF, Sandoval-Restrepo N, Mosquera-Valderrama YF, et al. Aerobic exercise training during pregnancy reduces depressive symptoms in nulliparous women: a randomised trial. J Physiother 2012;58:9-15.

78 Perales M, Refoyo I, Coteron J, et al. Exercise during pregnancy attenuates prenatal depression: a randomized controlled trial. Eval Health Prof 2015;38:59-72.

79 Dinc A, Kizilkaya Beji N, Yalcin O. Effect of pelvic floor muscle exercises in the treatment of urinary incontinence during pregnancy and the postpartum period. Int Urogynecol J Pelvic Floor Dysfunct 2009;20:1223-31.

80 Marques J, Botelho S, Pereira LC, et al. Pelvic floor muscle training program increases muscular contractility during first pregnancy and postpartum: electromyographic study. Neurourol Urodyn 2013;32:998-1003.

81 Mørkved S, Bø K, Schei B, et al. Pelvic floor muscle training during pregnancy to prevent urinary incontinence: a single-blind randomized controlled trial. Obstet Gynecol 2003;101:313-19.

82 Pelaez M, Gonzalez-Cerron S, Montejo R, et al. Pelvic floor muscle training included in a pregnancy exercise program is effective in primary prevention of urinary incontinence: a randomized controlled trial. Neurourol Urodyn 2014;33:67-71.

83 Stafne SN, Salvesen KA, Romundstad PR, et al. Does regular exercise including pelvic floor muscle training prevent urinary and anal incontinence during pregnancy? A randomised controlled trial. BJOG 2012;119:1270-80.

84 Mørkved S, Bø K. Effect of pelvic floor muscle training during pregnancy and after childbirth on prevention and treatment of urinary incontinence: a systematic review. Br J Sports Med 2014;48:299-310.

85 Bø K, Haakstad LA. Is pelvic floor muscle training effective when taught in a general fitness class in pregnancy? A randomised controlled trial. Physiotherapy 2011;97:190-5.

86 Bo K, Hilde G, Staer-Jensen J, et al. Does general exercise training before and during pregnancy influence the pelvic floor "opening" and delivery outcome? A 3D/4D ultrasound study following nulliparous pregnant women from mid-pregnancy to childbirth. Br J Sports Med 2015;49:196-9.

87 Jungheim ES, Travieso JL, Carson KR, et al. Obesity and reproductive function. Obstet Gynecol Clin North Am 2012;39:479-93.

88 Davenport MH, Steinback CD, Mottola MF. Impact of pregnancy and obesity on cardiorespiratory responses during weight-bearing exercise. Respir Physiol Neurobiol 2009;167:341-7. 
89 Mottola MF. Physical activity and maternal obesity: cardiovascular adaptations, exercise recommendations, and pregnancy outcomes. Nutr Rev 2013;71(Suppl 1):S31-6.

90 Chandrasekaran S, Levine LD, Durnwald CP, et al. Excessive weight gain and hypertensive disorders of pregnancy in the obese patient. J Matern Fetal Neonatal Med 2014:1-5.

91 Flick $A A$, Brookfield $K F$, de la Torre $L$, et al. Excessive weight gain among obese women and pregnancy outcomes. Am J Perinatol 2010;27:333-8.

92 Gaillard R, Durmus B, Hofman A, et al. Risk factors and outcomes of maternal obesity and excessive weight gain during pregnancy. Obesity 2013;21:1046-55.

93 Lamina S, Agbanusi E. Effect of aerobic exercise training on maternal weight gain in pregnancy: a meta-analysis of randomized controlled trials. Ethiop J Health Sci 2013:23:59-64.

94 Mudd LM, Owe KM, Mottola MF, et al. Health benefits of physical activity during pregnancy: an international perspective. Med Sci Sports Exerc 2013;45:268-77.

95 Ruiz JR, Perales M, Pelaez M, et al. Supervised exercise-based intervention to prevent excessive gestational weight gain: a randomized controlled trial. Mayo Clin Proc 2013;88:1388-97.

96 Mottola MF. Exercise prescription for overweight and obese women: pregnancy and postpartum. Obstet Gynecol Clin North Am 2009;36:301-16, viii.

97 Guendelman S, Pearl M, Kosa JL, et al. Association between preterm delivery and pre-pregnancy body mass (BMI), exercise and sleep during pregnancy among working women in Southern California. Matern Child Health J 2013;17:723-31.

98 Jukic AM, Evenson KR, Daniels JL, et al. A prospective study of the association between vigorous physical activity during pregnancy and length of gestation and birthweight. Matern Child Health J 2012;16:1031-44.

99 Barakat $R$, Stirling JR, Lucia A. Does exercise training during pregnancy affect gestational age? A randomised controlled trial. Br J Sports Med 2008;42:674-8.

100 Clapp JF III. Does exercise training during pregnancy affect gestational age? Clin J Sport Med 2009;19:241-3.
101 Owe KM, Nystad W, Skjaerven R, et al. Exercise during pregnancy and the gestational age distribution: a cohort study. Med Sci Sports Exerc 2012;44:1067-74.

102 Barakat R, Ruiz JR, Stirling JR, et al. Type of delivery is not affected by light resistance and toning exercise training during pregnancy: a randomized controlled trial. Am J Obstet Gynecol 2009;201:590.e1-6.

103 Bovbjerg ML, Siega-Riz AM. Exercise during pregnancy and cesarean delivery: North Carolina PRAMS, 2004-2005. Birth 2009;36:200-7.

104 Barakat $\mathrm{R}$, Pelaez $\mathrm{M}$, Lopez $\mathrm{C}$, et al. Exercise during pregnancy reduces the rate of cesarean and instrumental deliveries: results of a randomized controlled trial. J Matern Fetal Neonatal Med 2012;25:2372-6.

105 Tinloy J, Chuang CH, Zhu J, et al. Exercise during pregnancy and risk of late preterm birth, cesarean delivery, and hospitalizations. Womens Health Issues 2014;24:e99-e104.

106 Szumilewicz A, Wojtyla A, Zarebska A, et al. Influence of prenatal physical activity on the course of labour and delivery according to the new Polish standard for perinatal care. Ann Agric Environ Med 2013;20:380-9.

107 ljaiya MA, Aboyeji AP, Fakeye 00, et al. Pattern of cervical dilatation among parturients in llorin, Nigeria. Ann Afr Med 2009;8:181-4.

108 Melah GS, El-Nafaty AU, Massa AA, et al. Obstructed labour: a public health problem in Gombe, Gombe State, Nigeria. J Obstet Gynaecol 2003;23:369-73.

109 Orhue AA, Otubu JA. Prolonged labour. Textbook of obstetrics and gynaecology for medical students. Ibadan: Heinemann educational books, 2006:439-41.

110 Harper LM, Caughey AB, Roehl KA, et al. Defining an abnormal first stage of labor based on maternal and neonatal outcomes. Am J Obstet Gynecol 2014;210:536.e1-7.

111 Salvesen KA, Stafne SN, Eggebo TM, et al. Does regular exercise in pregnancy influence duration of labor? A secondary analysis of a randomized controlled trial. Acta Obstet Gynecol Scand 2014;93:73-9. 